\title{
IEDITORIAL
}

\section{Radial or femoral approach for rotational atherectomy: the drawbacks of data dredging}

\author{
Pierfrancesco Agostoni, Carlo Zivelonghi, Paul Vermeersch \\ HartCentrum, ZNA (Ziekenhuis Netwerk Antwerpen) Middelheim, Antwerp, Belgium
}

\section{RELATED ARTICLE}

by Januszek et al, see p. 529
Correspondence to: Pierfrancesco Agostoni, MD, PhD, HartCentrum, ZNA (Ziekenhuis Netwerk Antwerpen) Middelheim, Lindendreef 1, 2020 Antwerp, Belgium, phone: +3232803255 email: agostonipf@gmail.com Received: May 3, 2020. Accepted: May 4, 2020 Published online: June 25, 2020 Kardiol Pol. 2020; 78 (6): 508-509 doi:10.33963/KP.15450

Copyright by the Author(s), 2020
One of the first things taught in introductory statistics textbooks is that correlation is not causation. It is also one of the first things forgotten.

Thomas Sowell, born 1930

The radial approach has emerged in the last years as the favorite access site for percutaneous coronary diagnostic and interventional procedures. It has been even underlined in the latest guidelines: "the radial approach is recommended as the standard approach unless there are overriding procedural considerations." The class for this recommendation is I: condition for which there is evidence, general agreement, or both, that a given procedure or treatment is useful and effective. The level of evidence is A: data derived from multiple randomized clinical trials. ${ }^{1}$

Indeed, since our first meta-analysis published in 2004, ${ }^{2}$ already showing several benefits of the radial over the femoral approach, mainly in terms of local vascular complications and bleedings, evidence built up in the following years leading to stronger proof of benefit even in terms of major cardiac events, potentially including survival from cardiovascular death., Up to now, no major signals of technical "coronary-related" issues linked to radial access have emerged in the published trials and reviews. The radial approach seems thus to lead to similar procedural success rates like the femoral approach in cohorts undergoing "routine" percutaneous coronary interventions (PCIs).

The current major drawback of radial access is the rate of crossover due to technical inability to perform the procedure because of specific "radial-related" issues (eg, radial spasm or tortuosity/loops of the radial/brachial tract). For example, crossover from the radial to femoral approach occurred in $8.1 \%$ of the cases in the SAFARI (Safety and Efficacy of Femoral Access vs Radial Access in ST-segment Elevation Myocardial Infarction) trial and in $7.6 \%$ in the RIVAL (Radial vs Femoral Access for Coronary Intervention) trial. ${ }^{5,6}$ Interestingly, data from the RIVAL trial showed that all major bleedings occurring in the radial-access group were actually femoral complications. ${ }^{6}$ If similar results were confirmed in other trials, it would become evident that the necessary step to achieve even more relevant clinical benefits with the radial approach is that of minimizing crossover. If we were able to reduce this crossover towards much lower figures, ${ }^{7}$ this would have the potential to lead to the expected major clinical benefits using the radial approach (potentially abolishing major access site-related bleedings and maybe leading to the postulated mortality benefit).

In this issue of Kardiologia Polska (Kardiol Pol, Polish Heart Journal), an interesting subanalysis of the Polish nationwide registry of PCIs has been published, focusing on the comparison between the radial and femoral approaches when performing rotational atherectomy. ${ }^{8}$ In total, 2713 patients were treated with rotational atherectomy between 2014 and 2018 (thus a reasonably contemporary cohort). Interestingly, more patients were treated via radial than femoral access: 1653 (60.9\%) versus 1018 (37.5\%). In $42 \mathrm{pa}-$ tients $(1.5 \%)$ excluded from the analysis, another access site was used. The authors did not specify which one. If the access was ulnar or distal radial in some of the patients, these data could be pooled together with the radial data, as we believe that a "wrist" approach (including radial, ulnar, and distal radial) should be seen as a potential single group to be compared with femoral access. ${ }^{9-12}$ 
The authors found no major differences in several endpoints analyzed and in the total rate of periprocedural complications. However, in the subgroup analyzed with propensity score methods, they showed that rotational atherectomy performed with the radial approach led to a significantly higher risk of coronary perforation. The $P$ value for this difference was 0.04 , thus just below the significance limit. We have a few comments related to these findings.

First, multiple comparisons, even using advanced statistical methods such as propensity methods, are prone to the data dredging bias, also known as data fishing, data snooping, data butchery, and p-hacking (https://en.wikipedia. org/wiki/Data_dredging). Thus, the possibility that such a borderline significant $P$ value has been found by the play of chance is rather elevated. Conventional tests of statistical significance are based on the probability that a particular result would arise if chances alone were at work, and necessarily accept some risk of mistaken conclusions of a certain type. This level of risk is called the significance. When large numbers of tests are performed (like in the current analysis), some produce false results of this type; hence $5 \%$ of randomly chosen hypotheses might be (erroneously) reported to be significant at the $5 \%$ significance level by chance alone. When enough hypotheses are tested, it is virtually certain that some will be reported as statistically significant (even though this is misleading), since almost every data set with any degree of randomness is likely to contain some spurious correlations. Data dredging is an example of disregarding the problem of multiple comparisons.

Second, the authors did not provide information on the severity of the perforations reported. We believe this is also another important parameter that needs to be analyzed or at least discussed. Perforations without clinical consequences are substantially irrelevant if well managed. Perforations are important once they lead to relevant clinical sequelae. Indeed, in the paper, there is no mention of the periprocedural pericardial tamponade rate noted in the analyzed cohort. This would give a better idea of the impact of the perforations that occurred.

In conclusion, we believe the data presented in the article by Januszek et $\mathrm{al}^{8}$ do not weaken the use of the radial approach for PCIs, even when rotational atherectomy is foreseen. What is more, we consider the radial approach to be the "way-to-go" even for complex PCI, including rotational atherectomy, chronic total occlusions, and other complex subtypes. ${ }^{10-14}$ The only ingredients needed are expertise and time to build this expertise.

\section{ARTICLE INFORMATION}

DISCLAIMER The opinions expressed by the author are not necessarily those of the journal editors, Polish Cardiac Society, or publisher.

\section{CONFLICT OF INTEREST None declared.}

OPEN ACCESS This is an Open Access article distributed under the terms of the Creative Commons Attribution-NonCommercial-NoDerivatives 4.0 International License (CC BY-NC-ND 4.0), allowing third parties to download articles and share them with others, provided the original work is properly cited, not changed in any way, distributed under the same license, and used for noncommercial purposes only. For commercial use, please contact the journal office at kardiologiapolska@ptkardio.pl.

HOW TO CITE Agostoni P, Zivelonghi C, Vermeersch P. Radial or femoral approach for rotational atherectomy: the drawbacks of data dredging. Kardiol Pol. 2020; 78: 508-509. doi:10.33963/KP.15450

\section{REFERENCES}

1 Neumann FJ, Sousa-Uva M, Ahlsson A, et al; ESC Scientific Document Group. 2018 ESC/EACTS Guidelines on myocardial revascularization. Eur Heart J. 2019; 40: 87-165.

2 Agostoni P, Biondi-Zoccai GG, de Benedictis ML, et al. Radial versus femoral approach for percutaneous coronary diagnostic and interventional procedures; Systematic overview and meta-analysis of randomized trials. J Am Coll Cardiol. 2004; 44: 349-356.

3 Mason PJ, Shah B, Tamis-Holland JE, et al; American Heart Association Interventional Cardiovascular Care Committee of the Council on Clinical Cardiology; Council on Cardiovascular and Stroke Nursing; Council on Peripheral Vascular Disease; and Council on Genomic and Precision Medicine. An update on radial artery access and best practices for transradial coronary angiography and intervention in acute coronary syndrome: a scientific statement from the American Heart Association. Circ Cardiovasc Interv. 2018; 11: e000035.

4 Ferrante G, Rao SV, Jüni P, et al. Radial versus femoral access for coronary interventions across the entire spectrum of patients with coronary artery disease: a meta-analysis of randomized trials. JACC Cardiovasc Interv. 2016; 9: 1419-1434.

5 Le May M, Wells G, So D, et al. Safety and efficacy of femoral access vs radial access in ST-segment elevation myocardial infarction: the SAFARI-STEMI randomized clinical trial. JAMA Cardiol. 2020; 5: 126-134.

6 Jolly SS, Yusuf S, Cairns J, et al; RIVAL trial group. Radial versus femoral access for coronary angiography and intervention in patients with acute coronary syndromes (RIVAL): a randomised, parallel group, multicentre trial. Lancet. 2011; 377: 1409-1420.

7 Baumann F, Roberts JS. Evolving techniques to improve radial/ulnar artery access: crossover rate of $0.3 \%$ in 1,000 consecutive patients undergoing cardiac catheterization and/or percutaneous coronary intervention via the wrist. J Interv Cardiol. 2015; 28: 396-404.

8 Januszek R, Siudak Z, Malinowski KP, et al. Radial versus femoral access in patients treated with percutaneous coronary intervention and rotational atherectomy. Kardiol Pol. 2020; 78: 529-536.

9 Agostoni P, Zuffi A, Faurie B, et al. Same wrist intervention via the cubital (ulnar) artery in case of radial puncture failure for percutaneous cardiac catheterization or intervention: the multicenter SWITCH registry. Int J Cardiol. 2013; 169: 52-56.

10 Zivelonghi C, van Kuijk JP, Poletti E, et al. A "minimalistic hybrid algorithm" in coronary chronic total occlusion revascularization: procedural and clinical outcomes. Catheter Cardiovasc Interv. 2020; 95: 97-104.

11 Zivelonghi C, van Kuijk JP, Suttorp MJ, et al. Implementing a minimally invasive approach (combining radial approach, small guiding catheters and minimization of double access) for coronary chronic total occlusion intervention according to the hybrid algorithm: the Minimalistic Hybrid Algorithm. Int J Cardiol. 2019; 283: 84-87.

12 Budassi S, Zivelonghi C, Scott B, Agostoni P. (Bi-)ulnar access for percutaneous intervention of coronary chronic total occlusion: a case series. Cardiovasc Revasc Med. 2019 0ct 21. [Epub ahead of print].

13 Khan AA, Panchal HB, Zaidi SIM, et al. Safety and efficacy of radial versus femoral access for rotational atherectomy: a systematic review and meta-analysis. Cardiovasc Revasc Med. 2019; 20: 241-247.

14 Bakker EJ, Maeremans J, Zivelonghi C, et al. fully transradial versus transfemoral approach for percutaneous intervention of coronary chronic total occlusions applying the hybrid algorithm: insights from RECHARGE registry. Circ Cardiovasc Interv. 2017; 10: e005255. 